\title{
INFLUÊNCIA DA TEMPERATURA NA RESISTÊNCIA AO ETANOL DA LEVEDURA Saccharomyces cerevisae Y904
}

\author{
A. L. M. CASTRO ${ }^{1}$; I. R. ZATTI ${ }^{1}$; M. L. CRUZ ${ }^{1}$; F. M. COSTA ${ }^{1}$; \\ M. M. de RESENDE ${ }^{1}$ e E. J. RIBEIRO ${ }^{1}$; \\ ${ }^{1}$ Universidade Federal de Uberlândia, Faculdade de Engenharia Química. \\ E-mail para contato: mariana_lopes10@hotmail.com
}

\begin{abstract}
RESUMO - A demanda por bioetanol é crescente e contribui significativamente para a matriz energética do país. Tecnologias que permitam a sua produção de forma sustentável são de suma importância, como a fermentação com alto teor de etanol, que resulta em vantagens econômicas, sociais e ambientais. Em busca de menor gasto energético na produção do etanol, menor consumo de água, menor produção de vinhaça e redução nos níveis de contaminação bacteriana nas fermentações, o objetivo deste trabalho foi estudar a influência da temperatura na resistência da levedura Saccharomyces cerevisae Y904 ao etanol no processo fermentativo. Os resultados preliminares de fermentações em batelada alimentada realizadas em 20 , 25 e $32^{\circ} \mathrm{C}$ indicaram que as temperaturas mais baixas favoreceram o processo em termos de conteúdo e produção de álcool, mas resultou em tempos de fermentação mais elevados. A $25^{\circ} \mathrm{C}$ no processo descontínuo com alimentação, a concentração de etanol atingiu $17,36^{\circ} \mathrm{GL}$ (concentração volumétrica álcool, v/v).
\end{abstract}

\section{INTRODUÇÃO}

O Brasil, desde o início de 1970, tem sido o principal produtor de etanol no mundo, utilizando a cana-de-açúcar como matéria-prima. Etanol a partir da cana-de-açúcar com a sua natureza renovável já é um recurso que o Brasil pode utilizar como um dos substitutos para os combustíveis fósseis (LUO, VOET E HUPPES, 2009). Numa produção industrial de etanol viável, o processo de fermentação deve ser extremamente robusto e pouco afetado por pequenas alterações da matéria prima, além da minimização dos custos, obtenção do máximo rendimento em etanol, minimização na síntese de outros produtos (como glicerol e ácido láctico), minimização do tempo de fermentação, baixa contaminação bacteriana, manutenção da alta viabilidade do fermento, minimização da adição de produtos químicos (como ácidos, antibióticos e antiespumantes), minimização dos gastos com manutenção, minimização de gastos de energia e água e automatização das operações manuais (GOLDEMBERG et al.,2008; MISSAWA, 2009).

A fermentação descontínua pode levar a baixos rendimentos e/ou produtividades, quando o substrato adicionado de uma só vez no início da fermentação exerce efeitos de inibição, repressão, ou desvia o metabolismo celular a produtos que não interessam (CARVALHO e SATO, 2001a). O biorreator batelada será sempre usado como base para as 
comparações de eficiências atingidas com relação aos outros processos, mas a sua baixa eficiência estimula o surgimento de formas alternativas (SCHIMIDELL e FACCIOTTI, 2001). Os processos batelada alimentada nas suas várias modalidades têm se mostrado eficientes e versáteis na grande maioria dos processos fermentativos, inclusive nos de fermentação alcoólica. Em tais processos, especialmente naqueles com altas densidades celulares, a produtividade é alta devido ao grande número de células viáveis no meio em fermentação. A batelada alimentada permite o controle da concentração de açúcar, minimizando os efeitos de inibição pelo substrato e permitindo a adição do mesmo nos momentos mais propícios durante a fermentação (McNEIL e HARVEY, 1990).

Diferentes temperaturas afetam de forma distinta a atividade metabólica e o crescimento da levedura. Isso pode ser atribuído, não somente à genética das diferentes cepas, mas também à composição do meio de crescimento e a outros parâmetros como $\mathrm{pH}$, agentes químicos, desidratação osmótica, estado nutricional e fase de crescimento. As temperaturas ótimas para a produção industrial de etanol situam-se na faixa de 26 a $35^{\circ} \mathrm{C}$, mas, não raramente a temperatura nas destilarias alcança $38^{\circ} \mathrm{C}$. À medida que a temperatura aumenta, a contaminação bacteriana é favorecida e a levedura fica mais sensível à toxidez do etanol, o que implica uma diminuição da viabilidade das células (LIMA et al.,2001).

A produção máxima de etanol - Pmáx é a concentração máxima de etanol no qual o crescimento de células de levedura e produção de etanol são completamente inibidos (BAI, ANDERSON e MOO-YOUNG, 2008). As fermentações conduzidas a temperaturas mais baixas podem levar a uma maior resistência da levedura ao teor de etanol final e também uma menor geração de subprodutos do metabolismo celular devido ao menor estresse ao quais as células são submetidas. Assim, o objetivo deste estudo foi avaliar a influência da temperatura no desempenho de uma estirpe selecionada de Saccharomyces cerevisiae. Comparou-se a atividade do fermento, em processo batelada alimentada a $32^{\circ} \mathrm{C}$, que é a temperatura usual de muitas plantas brasileiras, com 20 e $25^{\circ} \mathrm{C}$, em termos de conteúdo de álcool e rendimento da fermentação.

\section{MATERIAIS E MÉTODOS}

\subsection{Microrganismos e Inóculo}

Utilizou-se uma cepa industrial Y-904 da levedura Saccharomyces cerevisiae em pó e produzida pela ABB Brasil. Na preparação do inóculo utilizou-se uma massa pré-determinada para cada experimento em um volume de $500 \mathrm{~mL}$. A hidratação das leveduras foi realizada por duas horas em água e sob agitação.

\subsection{Meio de cultura}

O meio de cultura para as leveduras foi composto de sacarose (concentração definida para cada experimento do planejamento fatorial), $\mathrm{KH}_{2} \mathrm{PO}_{4}(5 \mathrm{~g} / \mathrm{L}), \mathrm{MgSO}_{4} 7 \mathrm{H}_{2} \mathrm{O}(1 \mathrm{~g} / \mathrm{L})$, $\mathrm{NH}_{4} \mathrm{Cl}(1,67 \mathrm{~g} / \mathrm{L}), \mathrm{KCl}(1 \mathrm{~g} / \mathrm{L})$ e extrato de levedura $(6 \mathrm{~g} / \mathrm{L})$. Os reagentes utilizados foram todos de grau analítico, exceto a sacarose, a qual foi substituída por açúcar cristal comercial.

\subsection{Produção de bioetanol em biorreator}

Os experimentos foram realizados em um fermentador, modelo New Brunswick Multigen, com controles de agitação e de temperatura. O volume final de cada fermentação 
em batelada alimentada foi 1,5 L. Para determinar a resistência da levedura ao etanol, foram realizados processos em batelada alimentada com alimentação de sacarose feita quando no reator a concentração de sacarose era próxima de zero. O total de sacarose alimentada correspondeu a uma concentração de $300 \mathrm{~g} / \mathrm{L}$, se o reator fosse operado em batelada com o seu volume útil 1,5 L.

\subsection{Determinação das concentrações de açúcares e de etanol}

As concentrações de açúcares (sacarose, glicose e frutose), etanol e glicerol em todos os experimentos foram determinadas por cromatografia líquida de alta eficiência. As amostras foram diluídas, filtradas e injetadas no cromatográfico, marca Shimadzu, modelo $L C-20 \mathrm{~A}$ Prominence, utilizando coluna Supelcogel $\mathrm{Ca}$ e detecção por índice de refração de luz. A fase móvel utilizada foi água deionizada, a vazão da bomba foi de $0,5 \mathrm{~mL} / \mathrm{min}$, temperatura do forno de $80^{\circ} \mathrm{C}$ e volume de injeção de 20 microlitros.

\section{RESULTADOS E DISCUSSÃO}

A fim de se obter concentrações mais elevadas de etanol no caldo fermentado foram realizados experimentos nas temperaturas de 20,25 e $32^{\circ} \mathrm{C}$, em batelada alimentada. $\mathrm{O}$ açúcar foi adicionado ao reator sempre que a concentração de açúcar chegava a valores mínimos. Nesses experimentos, a levedura usada não sofreu qualquer processo de adaptação. Após completar o volume do reator por batelada alimentada, a concentração de sacarose correspondeu a $300 \mathrm{~g} / \mathrm{L}$ se o processo fosse operado em batelada convencional. Na Figura 1, os resultados obtidos a $20^{\circ} \mathrm{C}$, indicaram um tempo de fermentação de aproximadamente 72 horas e teor alcoólico de $15^{\circ} \mathrm{GL}$.

Figura 1 - Perfis de concentração de sacarose ( $($ ) e concentração de etanol $(\bullet)$ em função do tempo, para experimento conduzido em batelada alimentada a $20^{\circ} \mathrm{C}$.

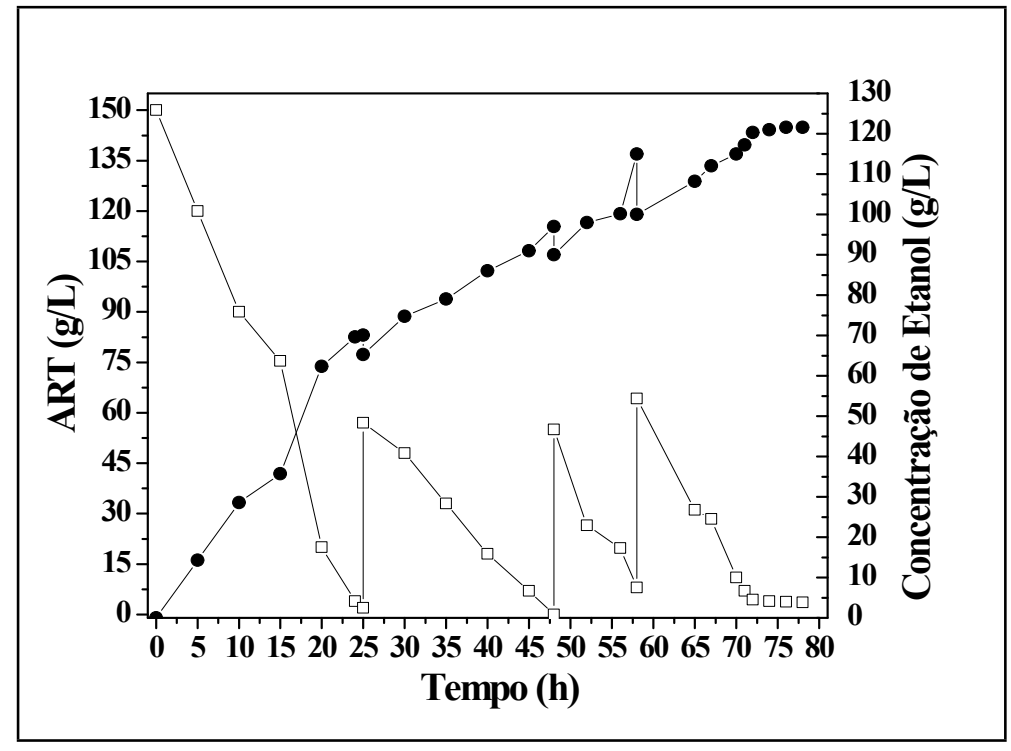


Para a fermentação realizada a $25{ }^{\circ} \mathrm{C}$, representada na Figura 2, o tempo de fermentação foi de 60 horas, o teor de alcoólico atingiu $17,36^{\circ} \mathrm{GL}$.

Figura 2 - Perfis de concentração de sacarose $\left({ }^{\circ}\right)$ e concentração de etanol $(\bullet)$ em função do tempo, para experimento conduzido em batelada alimentada a $25^{\circ} \mathrm{C}$.

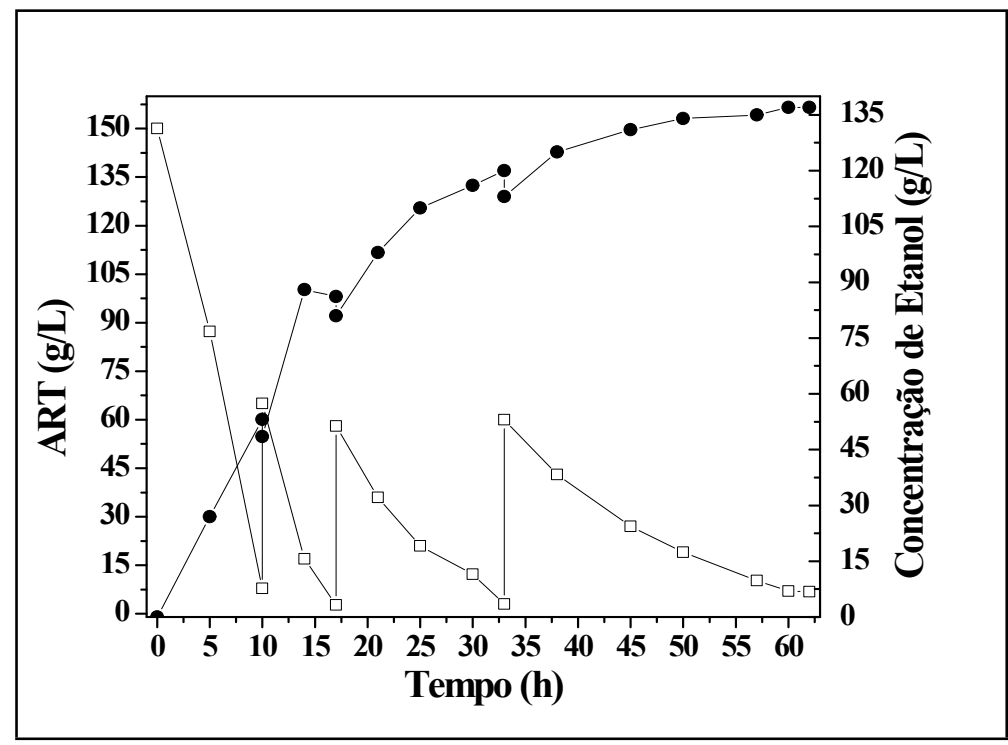

A fermentação conduzida a $32^{\circ} \mathrm{C}$ conforme Figura 4.3 , apresentou tempo de fermentação de 32 horas, a produção máxima de etanol chegou a $124 \mathrm{~g} / \mathrm{L}$, correspondendo a $15,7^{\circ} \mathrm{GL}$.

Figura 3 - Perfis de concentração de sacarose $\left({ }^{\circ}\right)$ e concentração de etanol $(\bullet)$ em função do tempo, para experimento conduzido em batelada alimentada a $32{ }^{\circ} \mathrm{C}$.

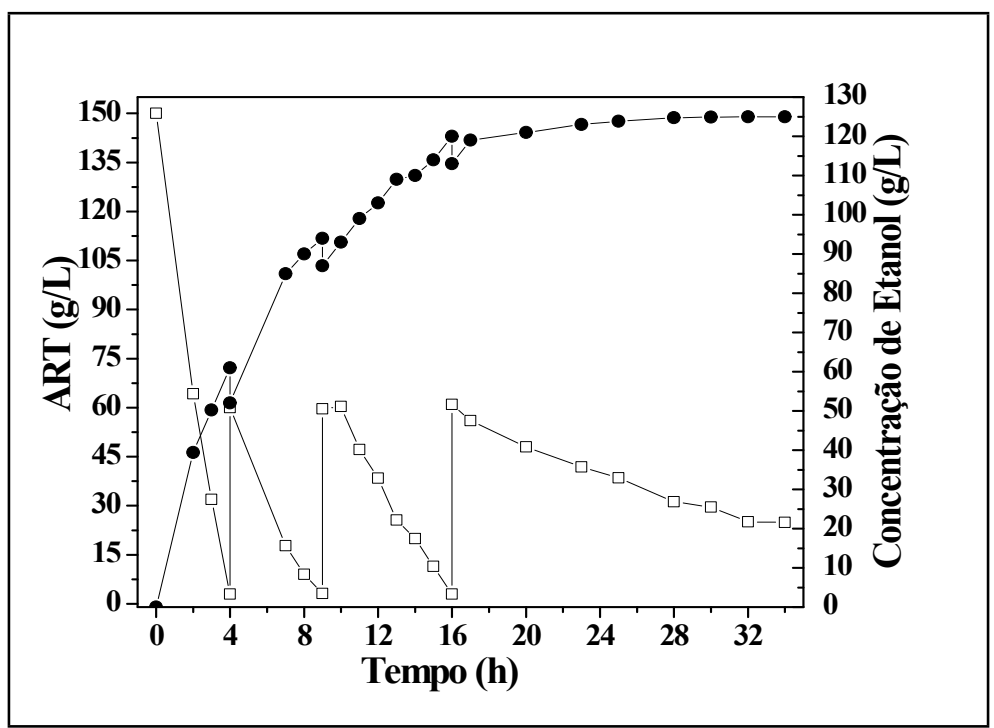


Estes resultados indicam que a levedura usada neste estudo, que é também utilizada industrialmente na produção de etanol, possui uma boa tolerância ao etanol na faixa de temperaturas estudada. Os tempos de fermentação foram bastante elevados, mas estratégias de alimentação no processo em batelada alimentada é uma variável que também já está sendo estudada. As concentrações de etanol obtidas neste estudo, utilizando esta estratégia de batelada alimentada, podem ser consideradas como parâmetro para a tolerância ao etanol na modelagem cinética na respectiva temperatura. Podemos observar pelos gráficos que mostram os perfis de concentração de açúcares redutores totais e etanol, dos experimentos conduzidos em batelada alimentada que a produção máxima $-\mathrm{P}^{\prime}{ }_{\max }$ é atingida quando essas concentrações se mantem constantes. Isso ocorre principalmente quando o etanol formado começa a inibir a levedura, cessando assim a formação de produtos. As concentrações finais de glicerol foram de $4,5 \mathrm{~g} / \mathrm{L}$ para a fermentações realizada a 20 e $25^{\circ} \mathrm{C}$ e de cerca de $10,0 \mathrm{~g} / \mathrm{L}$ para a fermentação realizadas $32^{\circ} \mathrm{C}$, o que indica que a levedura pode esta sofrendo um possível estresse a essa temperatura mais elevada.

Outro aspecto a ser considerado é o elevado valor da concentração de sacarose usada, que foi $300 \mathrm{~g} / \mathrm{L}$, em comparação com processo industrial. A inibição pelo substrato é um fenômeno comum em fermentações, e ocorre quando a concentração do substrato pode exceder um nível de tensão sobre o microrganismo. Andrews (1968) estudou os efeitos de inibição pelo substrato em reatores batelada e contínuo e propôs o modelo com inibição pelo substrato (BAI, ANDERSON e MOO-YOUNG, 2008).

Guidini (2013) quantificou a máxima concentração de etanol que a levedura C2/00 (cepa floculante de Saccharomyces cerevisiae) foi capaz de produzir durante o processo de fermentação alcoólica a $32^{\circ} \mathrm{C}$. Após o tempo de 30 horas de fermentação, a levedura sofreu inibição pelo produto, não consumindo mais substrato. A produção máxima de etanol foi de $110 \mathrm{~g} / \mathrm{L}$, aproximadamente $13,92 \%$ (v/v) e ao final da fermentação não houve crescimento da levedura, mantendo sua concentração inicial $(12 \% \mathrm{v} / \mathrm{v})$.

Oliveira (2008) obteve uma produção máxima de etanol por Saccharomyces cerevisiae de $72,1 \mathrm{~g} / \mathrm{L}$ e viabilidade celular de $86,4 \%$ utilizando inóculo de $40 \mathrm{~g} / \mathrm{L}$ em massa seca operando em batelada simples a $34^{\circ} \mathrm{C}$, utilizando $200 \mathrm{~g} / \mathrm{L}$ de sacarose inicial.

\section{CONCLUSÕES}

Foi possível concluir que a cepa Y904 de Saccharomyces cerevisiae estudada neste trabalho possui maior resistência ao etanol no processo fermentativo a $32^{\circ} \mathrm{C}$ em relação à outras cepas de Saccharomyces cerevisiae e a cepa C2/00, para praticamente o mesmo tempo de fermentação. Concluiu-se também que, nos processos de fermentação a temperaturas mais baixas, a resistência ao etanol é maior. Outro aspecto evidenciado no processo em batelada alimentada é a possibilidade de se obter concentrações de etanol superiores no caldo de fermentação, quando em comparação com o processo batelada convencional.

\section{AGRADECIMENTOS}

Os autores agradecem à Universidade Federal de Uberlândia e à Faculdade de Engenharia 


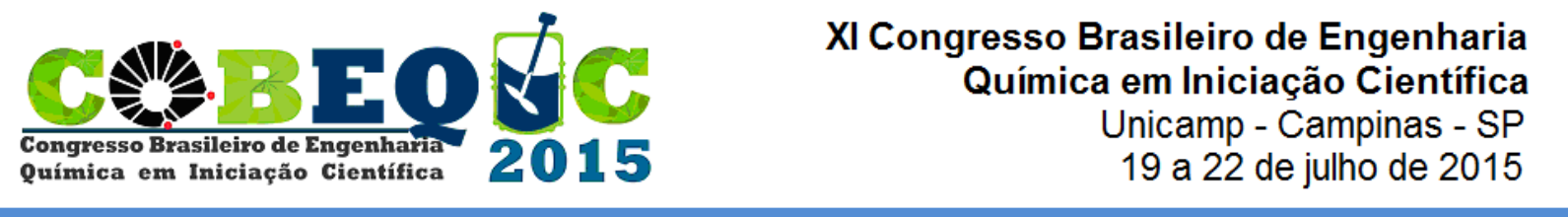

Química pela oportunidade em realizar este trabalho. Agradecem também ao apoio financeiro da Fapemig, da CAPES e do CNPq.

\section{REFERÊNCIAS}

ANDREWS, J. F. A mathematical model for the continuous culture of micro-organisms utilizing inhibitory substrates. Biotechnology and Bioengineering, v. 10, p.707-723, 1968.

BAI, F. W.; ANDERSON, W. A.; MOO-YOUNG, M. Ethanol fermentation technologies from sugar and starch feedstocks. Biotechnology Advances, v. 26, p. 89-105, 2008.

CARVAlHO, J. C. M.; SATO, S. Fermentação Descontínua. In: Schmidell, Willibaldo et al. (Coord.). Biotecnologia Industrial: Engenharia Bioquímica. São Paulo: Edgar Blücher, 2001a. p. 193-204. (Biotecnologia Industrial; v.2)

GOLDEMBERG, J.; COELHO, S. T.; GUARDABASSI, P. The sustainability of ethanol production from sugarcane. Energy Policy, v. 36, p. 2086-2097, 2008.

GUIDINI, C. Z.; MARQUEZ, L. D. S.; SILVA, H. A.; RESENDE, M. M.; CARDOSO, V.L.; RIBEIRO, E. J. Alcoholic Fermentation with Flocculant Saccharomyces cerevisiae in Fed-Batch Process. Applied Biochemistry and Biotechnology, v. 131, n.6, 2013.

LIMA, U. A.; BASSO, L. C.; AMORIM, H. V. In: LIMA, U. A. (Coord.). Biotecnologia Industrial: Processos Fermentativos e Enzimáticos. São Paulo: Edgard Blücher, 2001. p.1-43. (Biotecnologia Industrial; v.3)

LUO, L.; VOET, E. van der.; HUPPES, G. Life cycle assessment and life cycle costing of bioethanol from sugarcane in Brazil. Renewable and Sustainable Energy Reviews, v. 13, p. 1613-1619, 2009.

McNEIL, B. e HARVEY, L. M. Fermentation - a practical approach. $1^{\text {st }}$ ed. IRL PRESS at Oxford University Press. 1990.

MISSAWA, S. K. Modificação de linhagens industriais de Saccharomyces cerevisiae para o aumento da produtividade de álcool e floculação condicional. 150 f. Tese (Doutorado) - Instituto de Biologia, Universidade Estadual de Campinas, Campinas, 2009.

OLIVEIRA, K. F. Efeitos do ácido lático adicionado sobre a produção de etanol em fermentações com reutilização de células a $34^{\circ} \mathrm{C} .191 \mathrm{f}$. Tese (Doutorado) Universidade de São Paulo, São Paulo, 2008.

SCHMIDELL, W. ; FACCIOTTI, M. C. R. Biorreatores e Processos Fermentativos. Biotecnologia Industrial: Engenharia Bioquímica. São Paulo: Edgar Blücher, 2001. p. 179-192. (Biotecnologia Industrial; v.2) 